\title{
Diagnosing Appendicitis in Pregnancy Via Ultrasonography
}

\author{
Rohan Mangal ${ }^{1}$, Tej G. Stead ${ }^{2}$, Latha Ganti ${ }^{3}$, Javier Rosario ${ }^{4}$ \\ 1. Emergency Medicine, Johns Hopkins University, Baltimore, USA 2. Emergency Medicine, Brown University, \\ Providence, USA 3. Emergency Medicine, Envision Physician Services, Orlando, USA 4. Emergency Medicine, University
} of Central Florida College of Medicine, Orlando, USA

Corresponding author: Tej G. Stead, tej_stead@brown.edu

\begin{abstract}
The authors present a case of acute appendicitis during a first trimester pregnancy. Appendicitis in pregnancy is especially dangerous because perforation of the appendix increases the likelihood of maternal and fetal morbidity significantly. For this reason, it is important to diagnose and treat suspected appendicitis in pregnancy as soon as possible. The patient was diagnosed with appendicitis via a transabdominal ultrasound. She was provided antibiotics and underwent a laparoscopic appendectomy and recovered without complications.
\end{abstract}

Categories: Emergency Medicine, Obstetrics/Gynecology, Radiology

Keywords: pregnancy, appendicitis, laparoscopic appendectomy

\section{Introduction}

Appendicitis is the most common nonobstetric complication during pregnancy resulting in operation, occurring at a rate of one in every 500-2000 pregnancies [1-2]. However, an appendicitis during pregnancy is also more susceptible to complications. Most notably, pregnant patients are at greater risk of appendix perforation, $43 \%$ in pregnant women versus $4 \%-19 \%$ in general population [3]. Perforation presents serious risk for intraperitoneal infections and has shown a greater incidence for maternal and fetal death [4].

\section{Case Presentation}

A 21-year-old female, who was eight weeks pregnant with her first child, presented to the ED complaining of right lower quadrant pain. Her pain began rather abruptly while she was at work, and was associated with nausea. Her vital signs in the ED were temperature $37^{\circ} \mathrm{C}$, pulse 110 beats per minute, respirations 18 per minute, and blood pressure $122 / 81 \mathrm{mmHg}$, with oxygen saturation of $99 \%$ on room air.

Received 08/20/2019 Review began 08/25/2019 Review ended 08/31/2019 Published 09/04/2019

๑) Copyright 2019 Mangal et al. This is an open access article distributed under the terms of the Creative Commons Attribution License CC-BY 3.0., which permits unrestricted use, distribution, and reproduction in any medium, provided the original author and source are credited.
Physical examination confirmed tenderness in the lower right quadrant with guarding and rebound. Remainder of abdominal exam was negative. Laboratory evaluation demonstrated leukocytosis with a white blood cell count of $19.89 \times 10^{9}$ cells per liter (normal range $4-11 \times 10^{9}$ cells/L), with $81 \%$ neutrophils (normal range 37\%-74\%), indicating neutrophilia. Her chemistries were normal.

Transabdominal ultrasound (US) revealed an intrauterine gestational sac containing a fetal pole, evaluating the gestation at eight weeks, one day (Figure 1). There was blood flow to both ovaries and no adnexal lesions visible. A noncompressible fluid-filled, slightly hypervascular tubular structure was located in the right lower quadrant of the abdomen, measuring $16 \mathrm{~mm}$ in diameter with rebound tenderness, confirming acute appendicitis (Figures 2-3). 


\section{Cureus}

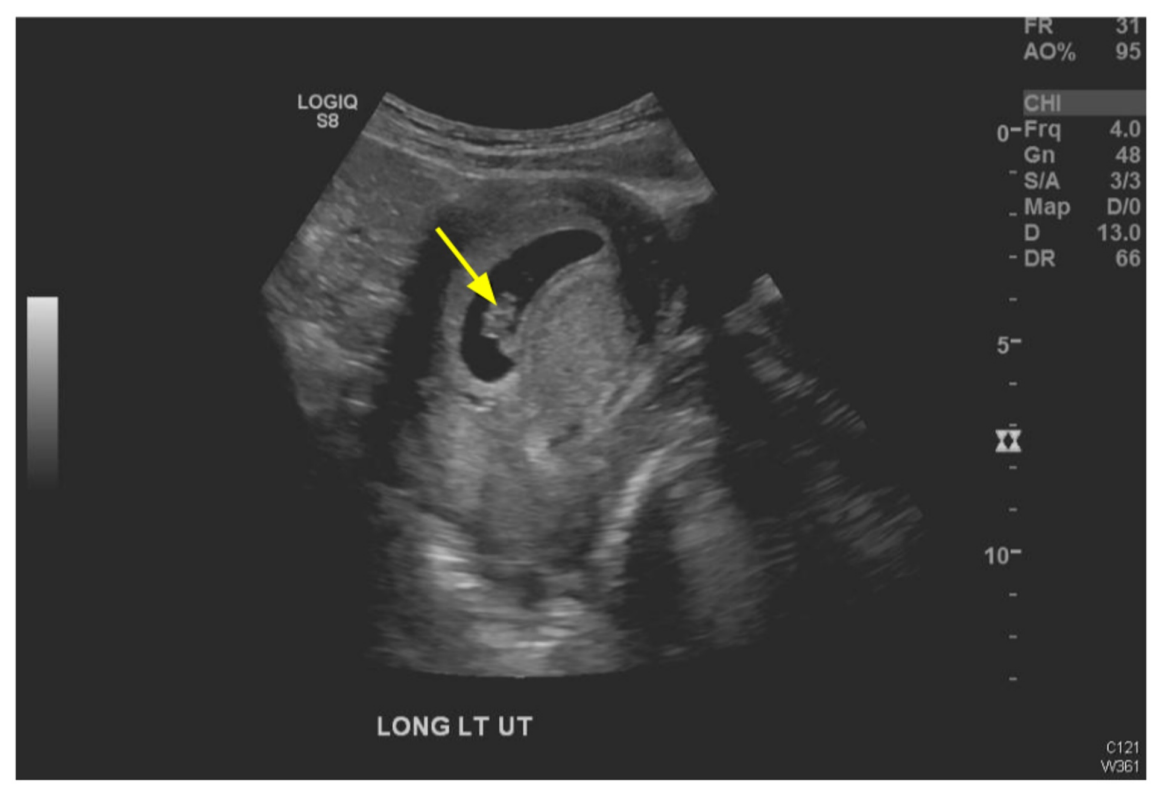

FIGURE 1: Sonogram demonstrating an intrauterine pregnancy.

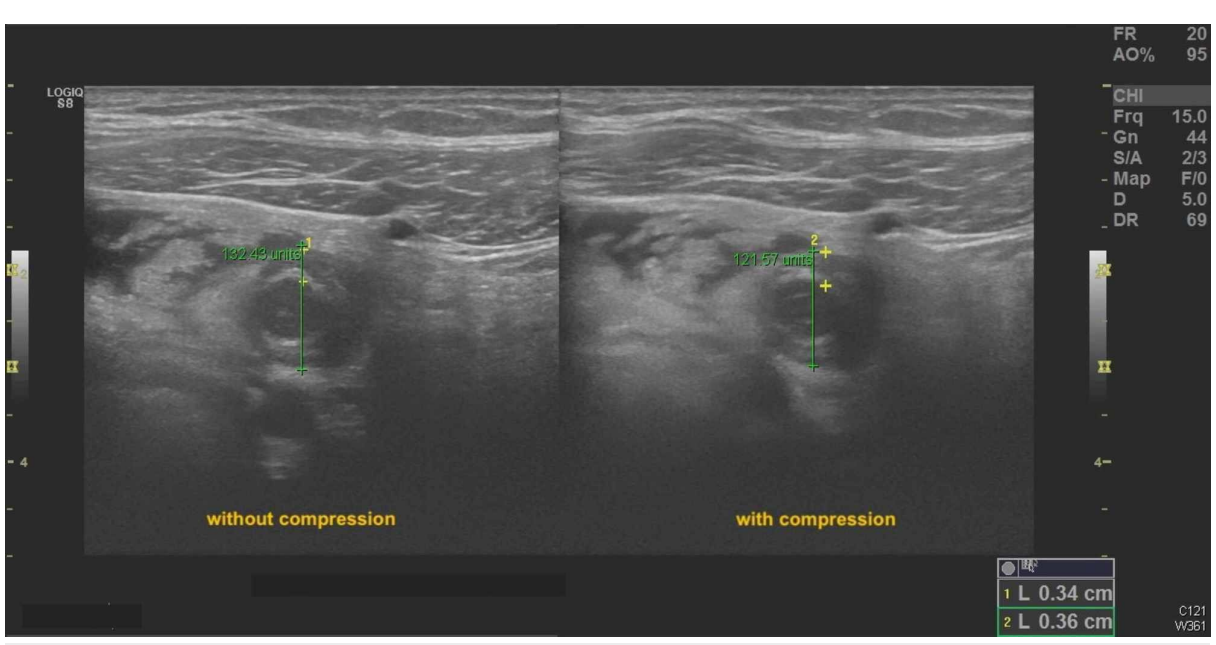

FIGURE 2: Sonogram demonstrating minimal compressibility of appendix on transverse view. Note the depth of the noncompressed and compressed appendix are almost equal. 


\section{Cureus}

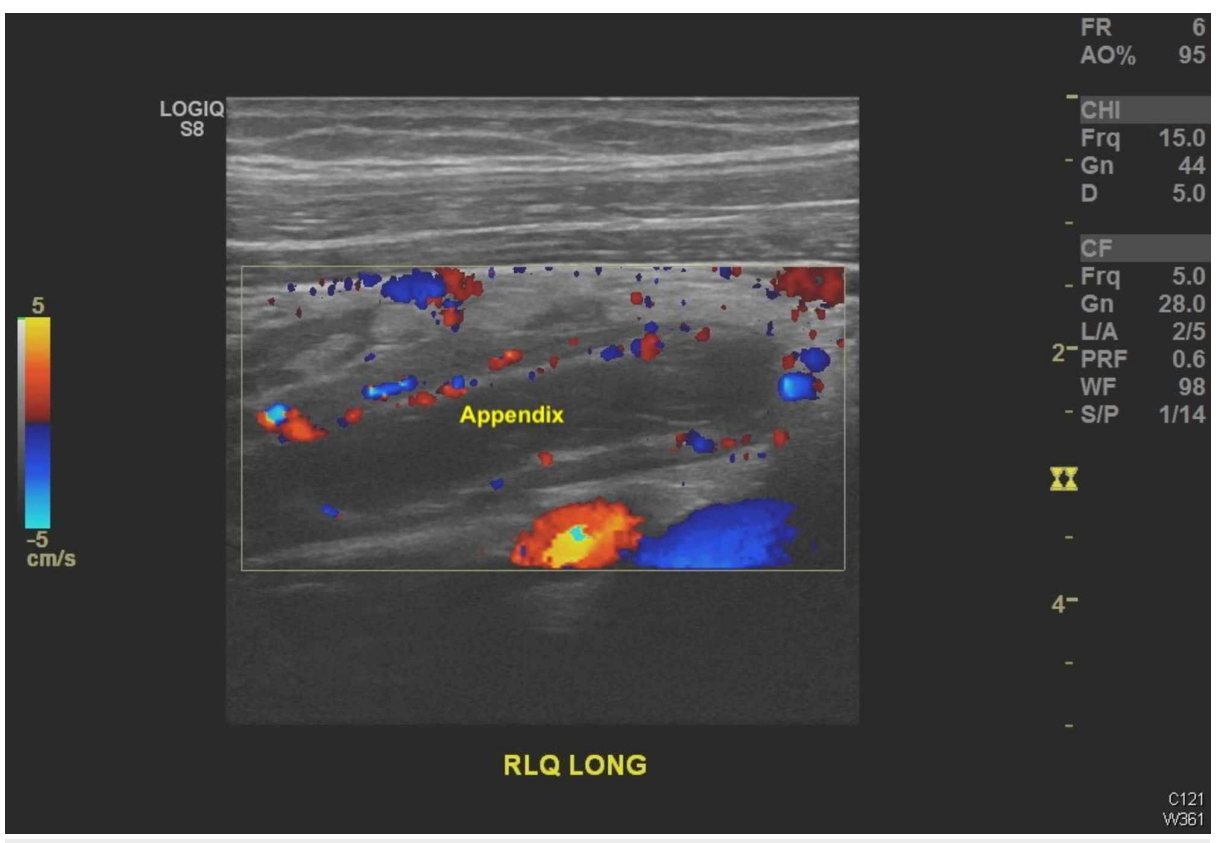

FIGURE 3: Sonogram demonstrating a long axis view of the appendix, a tubular structure that appears elongated beyond normal.

She received $3.375 \mathrm{~g}$ intravenous piperacillin-tazobactam and was taken to the operating room for a laparoscopic appendectomy. She did well postoperatively and had no complications. She was seen by the obstetric service the next day, and the pregnancy remained intact. Two weeks following her surgery, repeat ultrasonography demonstrated a properly progressing pregnancy with good fetal heart tones.

\section{Discussion}

A timely diagnosis is important for lowering risk of appendix perforation. Appendicitis diagnosis in pregnancy can become more convoluted the later the pregnancy stage. In our patient, the symptoms were relatively classic, and her slender body habitus made sonographic evaluation straight forward. A review of 22 cases shows that typical symptoms of appendicitis, including nausea, vomiting, and fever, are unreliable in pregnant patients with appendicitis who report abdominal pain [5]. Thus, an ultrasound may be necessary to confirm an appendicitis in expecting mothers.

Following diagnosis and the decision to operate, physicians decide between an open or laparoscopic surgery. In a review of 45 cases, 15 (33\%) had a successful laparoscopic appendectomy in the first trimester, while 22 (49\%) did in the second trimester-thus this operative technique is most often recommended within 26 weeks of pregnancy [6]. A meta-analysis [7] covering 905 laparoscopic appendectomies and 3789 open appendectomies found no significant difference in the rates of fetal loss or preterm delivery between open and laparoscopic appendectomy.

Ultrasonography is a highly useful imaging modality for diagnosing acute appendicitis. In a review of 181 patients with acute appendicitis, appendix diameter was found to be highly predictive. Appendicitis was present in $2.6 \%$ of cases when diameter was $\leqslant 6 \mathrm{~mm}, 65 \%$ of cases when between 6 and $8 \mathrm{~mm}$, and $96 \%$ of cases when $\geqslant 8 \mathrm{~mm}[8]$. Other signs include noncompressibility of the appendix and wall thickness $\geqslant 3 \mathrm{~mm}$. Overall, in a review of 9121 patients across 25 studies, US had a sensitivity of $83.7 \%$, specificity of $95.9 \%$, and an accuracy of $92.2 \%$ in diagnosing acute appendicitis [9]. Sometimes US is inconclusive for appendicitis due to patient body habitus or intestinal gas. In these situations, MRI is the imaging modality of choice, with sensitivities and specificities of $80 \%-100 \%$ and $93 \%-98 \%$, respectively [10].

In our patient's case, the appendix diameter was almost double the upper-end of diagnostic values, and the patient was taken expeditiously to the operating room without any further studies. This was extremely important to prevent rupture of the appendix which would have resulted in increased morbidity to both mother and the fetus. Up to $26 \%$ of first trimester pregnancies result in miscarriage [11], and $43 \%$ of women report having one or more first trimester miscarriages [12]. Given this baseline risk, our patient was at increased risk of miscarriage due to the appendicitis and ensuing surgery. However, due to the prompt action by the clinical teams, the patient and fetus did well. Somewhat unique to this case is the ability for us to follow the patient, and being able to document a healthy pregnancy both immediately postop as well as two weeks afterward. 


\section{Conclusions}

Appendicitis is not an uncommon complication during pregnancy. A timely ultrasound can confirm the diagnosis of appendicitis. Measures should be taken to avoid appendix perforation, as this can lead to fetal mortality. A laparoscopic appendectomy should be considered for treating related cases of appendicitis during pregnancy.

\section{Additional Information \\ Disclosures}

Human subjects: Consent was obtained by all participants in this study. Conflicts of interest: In compliance with the ICMJE uniform disclosure form, all authors declare the following: Payment/services info: All authors have declared that no financial support was received from any organization for the submitted work. Financial relationships: All authors have declared that they have no financial relationships at present or within the previous three years with any organizations that might have an interest in the submitted work. Other relationships: All authors have declared that there are no other relationships or activities that could appear to have influenced the submitted work.

\section{Acknowledgements}

This research was supported (in whole or in part) by HCA Healthcare and/or an HCA Healthcare affiliated entity. The views expressed in this publication represent those of the author(s) and do not necessarily represent the official views of HCA Healthcare or any of its affiliated entities.

\section{References}

1. Holzer T, Pellegrinelli G, Morel P, Toso C: Appendectomy during the third trimester of pregnancy in a 27year-old patient: case report of a "near miss" complication. Patient Saf Surg. 2011, 5: 10.1186/1754-9493-511

2. Selzer DJ, Stefanidis D: Surgical emergencies in the pregnant patient. Adv Surg. 2011, 5:161-177. 10.1016/j.yasu.2019.04.008

3. Freeland M, King E, Safcsak K, Durham R: Diagnosis of appendicitis in pregnancy. Am J Surg. 2008, 198:753758. 10.1016/j.amjsurg.2009.05.023

4. Somani RA, Kaban G, Cuddington G, McArthur R: Appendicitis in pregnancy: a rare presentation . Can Med Assoc J. 2003, 168:1020.

5. Tracey M, Fletcher HS: Appendicitis in pregnancy. Am Surg. 2000, 66:555-559.

6. Lemieux P, Rheaume P, Levesque I, Bujold E, Brochu G: Laparoscopic appendectomy in pregnant patients: a review of 45 cases. Surg Endosc. 2009, 23:1701. 10.1007/s00464-008-0201-9

7. Lee SH, Lee JY, Choi YY, Lee JG: Laparoscopic appendectomy versus open appendectomy for suspected appendicitis during pregnancy: a systematic review and updated meta-analysis. BMC Surg. 2019, 19:10.1186/s12893-019-0505-9

8. Trout AT, Towbin AJ, Fierke SR, Zhang B, Larson DB: Appendiceal diameter as a predictor of appendicitis in children: improved diagnosis with three diagnostic categories derived from a logistic predictive model. Eur Radiol. 2015, 25:2231-2238. 10.1007/s00330-015-3639-x

9. Al-Khayal KA, Al-Omran MA: Computed tomography and ultrasonography in the diagnosis of equivocal acute appendicitis. A meta-analysis. Saudi Med J. 2007, 28:173-180.

10. Thompson MM, Kudla AU, Chisholm CB: Appendicitis during pregnancy with a normal MRI. West J Emerg Med. 2014, 15:652-654. 10.5811/westjem.2014.7.22988

11. Wilcox AJ, Weinberg CR, O'Connor JF, et al.: Incidence of early loss of pregnancy . N Engl J Med. 1988, 28:189-194. 10.1056/NEJM198807283190401

12. Cohain JS, Buxbaum RE, Mankuta D: Spontaneous first trimester miscarriage rates per woman among parous women with 1 or more pregnancies of 24 weeks or more. BMC Pregnancy Childbirth. 2017, 17:437. 10.1186/s12884-017-1620-1 